\title{
DEPRESSIVE SYMPTOMATOLOGY IN HOSPITALISED CHILDREN
}

\author{
M. Rangaka, C. Rose and L. Richter
}

\begin{abstract}
This study was undertaken to determine the extent and noture of deptessive symptoms exhibited by black South African children during haspitalisation for or thopaedic procedures. Social factors associated with the risk for depression, in response to hospitalisation, were also examined Pre- and post-test assessments were conducted on a sample of 30 chitdren, aged beween 6 and 12 years. The assessment entailed a structured interview, together with the following. psychometric instruments: A Global Mood Scale, a Depressive Symptoms Checklist, a Hospital F earsRating Scale and a SelfReport Depression Rating Scale A large proportion of the children were rared by watd sisters as showing high levets of depressive symptomatology two weeks after admit ston to hospital As expected. discrepancies were found between adut and child self ratings of depression. The results of this study indicate that hospitatisation for orthopaedic chitd patients is associated with the development of depressive symptomatology it is suggested that emphosis be placed on the development of supportive programmes and procedures aimed ot maximising chitdren's coping responses to hospitalisation, particularly for children who find themselves isolated from theit communtiles and fomilles, as. a result of both centralised health senvices and poor sacio-economic conditions.
\end{abstract}

\section{OPSOMMING}

Hierdie studie is onderneem om die onveang en aard tan depressiewe simptome onder swart Suid Afrikaonse kinders, tydens hospitalisasie vir orropediese redes te bepaat Sosiale faktore wat lor die moonitikheid van depressie kan bydtra as gevolg van hospitalisasie. is ook ondersoek. Voor en na - toets eval luasies is onderneem op in groep van 30 kinders tussen die ouderdomme 6 en 12 jaar. Die evaluaste het die volgende behels 1 i gestruktureerde onderhoud sowel os die volgende psigometriese toetse. WGobat Mood Scate, Depressive Symptoms Cheeklist. Hospital Fears Rating Scale' en "n "Self Report Depression Rating Scale" Volgens n evaluasie wat deur die saalsusters onderneent is her $n$ grool aontal kinder s wee weke na opname in die hospitad d depressiewe simptone getoon. Sekere ver skille tussen volwasse etalueering en kinder seff evalueering is gevind Die uitslae van die studie toon dat hospttaltsaste van ortopediese kinderpasiente gessowieer word met die ontwikketing van depressieve simptome Daar word loorgestel dat programme en prosedures wal ondersteuning a an kinders wat hospitatisasie noet onder gaan, ontwikkel word ther val die klem op kinders wat hilself getsoleerd

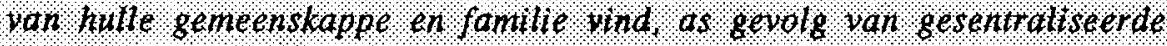
gesondheidsdienste asook lae sosio ekonomiese omstandighede.

\section{Introduction}

Several studies have indicated that iliness and hospitalisation are risk factors for the development of depression in children, particularly in cases of multiple admissions or prolonged hospitalisation (Blumberg, 1977; Bowlby, 1960; Rutter, 1979, Spitz, 1945; Trad, 1987). According to a recent review, at least $20 \%$ of children admitted into hospital display some degree of behaviourial or emotional disturbance (Yap, 1988). These reactive disturbances have not been found to persist for long periods after discharge from hospital, especially when children return to warm and supportive family environments in which every effort is made to help the child regain his or her equilibrium.

In Europe and North America, programmes have been developed to prepare children for hospitalisation and surgery, and to support them during hospitalisation, in order that negative emotional consequences during hospitalisation can be minimised and adverse effects on future adjustment averted.
In hospital, children are separated from parents, siblings, peers and familiar environments. This separation deprives them of the psychological and social support necessary for adaptation to the strange surroundings and events, and sometimes also to pain and discomfort. This social and psychological deprivation frequently leads to grief and feelings of loss, with subsequent depressive symptomatology (Lambert, 1984). It has been suggested that surgery, in particular, poses a significant risk for the child. In an unprepared child, surgical procedures may give rise to fears of loss of bodily parts, and may precipitate an overall concern with body image. Surgery often also implies pain and restrictions on movement and physical activities (Blumberg, 1977). According to the psychoanalytic perspective, the experience of surgery may evoke fantasies in children, of being attacked, mutilated, castrated or punished (Freud, 1952). These fantasies may be reinforced through misunderstandings of normal hospital or surgical procedures, as perceived by a frightened or confused child.

Maternal separation often elicits depressive-like symptoms (Reite, Short, Seiler \& Pauley, 1981) and it has been suggested that one of the greatest sources of distress for hospitalised children is separation from customary care-givers (usually the mother). This view is supported by studies which show that the presence of an emotionally supportive care-giver during hospitalisation significantly reduces the amount of distress and disturbance evidenced by hospitalised children (Lambert, 1984).

A number of factors have been shown to relate to children's adjustment to hospitalisation. For example, the age of the child is an important determinant of adaptation, with pre-school children showing more adverse reactions than older children (Langford, 1961; Yap, 1988). This age difference is presumed to be due to the enhanced coping capacity of older children and their greater receptivity to explanations and reassurances (Blumberg, 1977; Lambert, 1984; Langford, 1961).

It is probable that illness, hospitalisation and surgery have different meanings for and impacts on children from different cultural and social groups. These differences may be due, amongst other factors, to the influence of prior and current child-family relationships. As was mentioned before, one of the greatest sources of distress for hospitalised children is separation from the mother (Bowlby, 1980; Yarrow, 1964). In South African many black 
children are reared in extended families with multiple caretaking systems, whether by choice and tradition, or by force of circumstances. Even when both biological parents are present in the home, tradition entails that every adult in the household take part in child care. In addition, harsh economic and socio-political conditions have resulted in children being separated from their parents for weeks or months in the first few years of life. These conditions promote communal childrearing which, in turn, facilitates the establishment of intimate and strong attachments to adults other than parents (Rutter, 1981). These other child-adult relationships may mitigate against the trauma of maternal separation under stress, as occurs with hospitalisation.

On the other hand, an increased risk of problem behaviours in response to hospitalisation has been found to be associated with coming from a deprived and disadvantaged home (Yap, 1988). In addition to this general risk, other circumstances may affect black South African children's experiences of hospitalisation. For example, socioeconomic conditions, as well as long distances from urban health services, make it difficult for parents to pay regular visits to their children in hospital. The ability of parents to visit their children has been found, in other studies, to influence the child's experience of hospitalisation (Langford, 1961).

Poverty and the corresponding social and emotional stressors for children may imply, however, that better conditions for children pertain in hospital as compared to home (Robins, 1987; Yap, 1988). In hospital, children may enjoy regular and wholesome meals, as well as encounter, for the first time, sheets and a pillow, and a bed to him-or herself (Langford, 1961). They may also find themselves surrounded by attentive and concerned adults who have the time to respond to and meet their needs.

There is, in general, very little literature on depression in black South African children, and no studies which we could trace on children's depressive symptoms during hospitalisation. This study was undertaken to determine the extent and nature of depressive symptoms exhibited by black South African children during hospitalisation; and to identify some of the social factors which may be associated with the risk for depression precipitated by hospitalisation. It is hoped that material of this kind will be useful in promoting and developing preparation and support programmes for children admitted to hospitals in South Africa.

\section{Method}

\section{Sample}

Pre- and post-test assessments were conducted on a sample of 30 children drawn from consecutive admissions to the orthopaedic wards in a large teaching hospital outside Pretoria. All the children were aged between 6 and 12 years and only new admissions to hospital were included in the study. Children who were hospitalised with a parent or care-giver were excluded, as were children suffering from a chronic disease or mental disability. The intention was to examine the effects of hospitalisation isolated, as far as possible, from the effects of chronic illness.

\section{Procedure}

The complete assessment of each child included a structured interview, a daily record of visits by relatives, as well as the following psychological measures:

A Global Mood Scale, consisting of an adult rating of the direction (rated on a scale from 1-7) of a child's overall mood during the preceding fortnight. The scale was developed by Vernon, Foley and Schulman (1967) but for the purpose of this study, the language of the original scale was modified to make it more appropriate. Essentially, the scale measures the overall distress level of the child, from "1. Attentive, active and/or interested in play or other constructive activity" to "7. Screaming, intense and constant crying, difficult to console or distract".

- A Hospital Fears Rating Scale, entailing an 8 item self-rating scale tapping the child's reaction to the environment, staff and procedures of the hospital. The scale used in the present study was adapted from the original scale developed by Schere and Nakamura in 1968 , and the modified version was in accordance with more recent developments (Melamed \& Siegel 1975). An example of an item, which had to be answered with a "yes" or "no", is as follows" "There is something wrong with my body that needs to be put right."

- A Depressive Symptoms Checklist, based on the DSM-III(R) (American Psychiatric Association, 1987), and completed after interviewing the parent or ward sisters about the child's behaviour during the preceding two weeks. The purpose of this checklist was to arrive at a diagnosis of depression according to standard criteria. The following eight behaviours were checked as being present or absent during the past week: loss of weight, insomnia, hypersomnia, excessive motor activity, retarded motor activity, loss of energy, lack of concentration and self-destructive behaviour.

\section{A Self-Report Depression Rating Scale} (Asarnow \& Carlson, 1985) comprising 26 items on which children rated themselves according to whether they experienced the feelings referred to on a 3-point scale, ranging from always, to sometimes, to never. This scale is a modified version of Birleson's Depression Self-Rating Scale (1981) The scale has been used in previous cross-cultural studies and the structure and wording of the scale is regarded as being easy for children to understand (Asarnow \& Carlson, 1985). Examples of the items as: "I feel like crying", "I like to have fun", "I feel very lonely" and "All I can see ahead of me is unpleasantness rather than pleasantness".

According to Asarnow and Carlson (1985) the scale facilitates differentiation between depressed and non-depressed children, since as Kazdin (1990) states, the items in the scale reflect affective, cognitive and behavioral symptoms. The concurrent validity of the scale, assessed by the correlation between the original version of the scale and the Clinical Depression Inventory is good $(r=0,81)$, as is that of the modified version $(r=0,82)$. The internal consistency of the modified version is also reported to be good (Asarnow \& Carlson, 1985)

The rating scales were translated from English into Setswana and checked by an independent clinical psychologist for accuracy of interpretation. The translated versions of all the measures were assessed in a pilot study of 10 children and in interviews with nursing staff in the orthopaedic ward. On the basis of the pilot study, the language used in some items of the Depression Self-Rating Scale had to be simplified since the translation of the original language used in the scale was too difficult for the younger children to understand. The Global Mood Scale and the Depressive Symptoms Checklist were given to the ward sisters to check if they understood the type of information required by these instruments. Any misunderstandings were cleared and all items were clarified by discussions with the staff.

A record of daily visits was kept because, as previously mentioned, the literature suggests that contact with family and care-givers may militate against depressive symptoms developing amongst hospitalised children. Siegel's (1988) review of the assessment of children's emotional responses to hospitalisation and health care procedures, suggests that both the Global Mood Scale and the Hospital Fears Rating Scale are necessary measurements in studies of depression amongst hospitalised children. Clearly, both excessive fear and distress will predispose children to developing depressive symptoms in hospital. The Depressive Symptoms Checklist was included to arrive at a standard diagnosis of depression, according to DSM-III(R) criteria. A self-report Rating Scale was included to assess children's subjective feelings of depression.

The structured interview was conducted by the first author with the child's care-giver and was completed to obtain basic biographical and 
historical data; for example, educational level of parents, income, household density, type of housing, number of children and the index child's position in the family. The care-giver was also questioned about the index child's history of illness and hospitalisation, as well as the child's exposure to alternate care-givers, whether in or outside the home. On admission, the Self-Rating Depression Scale was administered to the child by the first author, while the Global Mood Scale was completed with the help of one of the child's parents, or other primary care-giver. The Depressive Symptoms Checklist was also completed with the help of a primary care-giver, by relating the presence or absence of symptoms to the child's behaviour during the two weeks preceding hospitalisation. After two weeks, the Depression Self-Rating Scale was re-administered and the Hospital Fears Rating Scale was completed, according to the responses of the child, by an independent investigator (i.e. an intern clinical psychologist in her final year of training). The Global Mood Scale and the Depression Symptom Checklist were also re-administered in consultation with the ward sisters.

\section{Results}

\section{Characteristics of the sample}

In general, the families of the children in the study sample were of a very low socioeconomic class: a third of both mothers and fathers had received only primary education, and more than a third of both parents were employed as unskilled labourers. Although not always reliably determined, the mean household income was reported to be $\mathrm{R} 532$ per month, with a range from R92 to $\mathrm{R} 1712$. The mean number of people living in each household was 7 , with a range from 32 to 15 people.

The mean age of the children was 9 years (range 6-12 years), and the sample consisted of 14 boys and 16 girls. All the children lived in the same household as their mother, but fathers were present in the homes of only 18 children. A third of the sample had more than three siblings and all the children had at least one sib.

The children were all orthopaedic patients, with eighteen children (60\%) hospitalised for trauma (mostly fractures), 9 children $(30 \%)$ for reconstruction or repair (for example, of a clubfoot), and the remaining $10 \%$ (3 children) for assessment and diagnosis.

\section{Children's Self-Rating of Depressive Symptoms}

On the depression self-rating scale, there was a small overall increase in scores from the pre-to the post-test. However, individual differences are so great that group results obscure the main findings. Seven children (23\%) showed a marked increase in self-rated depressive symptoms during the two-week period of hospitalisation under study.
Nineteen children (63\%) showed little change in self-rated symptoms during the period between assessments, but their rated symptomatology was already high on admission and remained relatively high throughout the period of hospitalisation studied. The remaining children rated themselves as experiencing a decrease in symptoms after the two-week period as compared to their scores on admission.

The symptoms reported by children who evidenced a marked increase on the second rating, as well as the children whose symptomatology remained at a high level throughout the period of hospitalisation, included feelings of anhedonia, hopelessness, loneliness and boredom, as well as bad dreams, loss of appetite and stomach aches. The most commonly reported symptom of depression after two weeks of hospitalisation was endorsement of the item "I feel very lonely", a response made by half $(47 \%)$ of the sample. Items on the self-rating scale which yielded an increase of $10 \%$ or more in the sample from the first to the second rating, included stomach aches, feelings of sadness and feelings of isolation. One child reported suicidal thoughts at admission and at the time of the second assessment. Sleeping problems were not reported by any children in the sample, at either admission or later.

\section{Adult Ratings of Distress and Depressive Symptomatology}

Parent ratings of the mood which characterised their children for the two weeks preceding hospitalisation was generally positive with few children rated as having distressed or depressive mood states, as measured on the Global Mood Scale (GMS). After being hospitalised for two weeks, $87 \%$ of the children showed an increase in distress, while $13 \%$ of the children showed either no changes or a decline on the GMS as rated by the ward sisters.

No parent reported the presence of depressive symptoms in their child during the two week period preceding admission to hospital. Symptoms under investigation comprised those listed in the DSM-III(R): a depressed or irritable mood, or anhedonia, and at least four of the following symptoms - increased mood problems, weight loss, insomnia or hypersomnia, excessive or retarded motor activity, loss of energy, lack of concentration, or self-destructive behaviour. After two weeks of hospitalisation the children were rated by the ward sisters according to the presence or absence of the same symptoms. Eighty three percent of the children were rated as showing a depressive syndrome while only $17 \%$ of the children were rated as being fee of depressive symptoms essential for the DSMIII(R) diagnosis. Apart from a depressed mood or anhedonia, the frequency of symptoms rated as being displayed by children on the second rating were, as follows: $43 \%$ had lost weight, $40 \%$ showed loss of energy, $33 \%$ of the children were judged to be suffering from insomnia and $30 \%$ evidenced retarded motor activity. None of the children were rated as manifesting self-destructive behaviour.

\section{Self-versus Adult Ratings}

As might be expected, there was a marked discrepancy between self- and adult ratings of depressive symptomatology for 11 children; for ten of these cases, the other-rating was positive for depression, whereas self-rating indicated an absence of depressive feelings. However, in 19 instances, child and adult ratings were in agreement, and in 14 cases $(47 \%)$ both concurred regarding the presence of symptoms of depression, whether subjectively or objectively assessed.

\section{Hospital Fears Rating Scale}

According to the responses given to the Hospital Fears Rating Scale, it appears that only a third of the children found the unfamiliar environment and the equipment frightening. More than half indicated that they did not find it stressful to come into contact with doctors and nurses, and over $70 \%$ of the children claimed that they did not find their confinement to bed frustrating. In contrast close to half the children found it frightening to be separated from home and family, and a similar proportion of children indicated that they were disappointed or angry with their parents for bringing them to hospital.

Some of the items on this scale do not actually assess fears, but rather tap the child's general feelings and experiences during hospitalisation, as well as their ideas about the meaning of their disorder. For example, 15 children (50\%) endorsed the item "There is something wrong with my body that needs to be put right". Of the children who endorsed this item, ten were admitted with different forms of fractures, three for repair of congenital abnormalities and two for diagnosis. That is, children's endorsement of this item indicated a realistic appreciation of their current bodily state and the implications of their hospitalisation.

\section{Visits in hospital}

Children whose mother was their primary daily care-giver, tended to receive more visits in hospital than children who were mainly looked after, on a day-to-day basis, by relatives or friends. Fifty eight percent of the former group received between 2 and 7 visits in the two-week period of hospitalisation under study, while $50 \%$ of the children with other care-givers received either no visits or only one visit during the same period. Maternal employment only partially accounted for the difference in the number of visits children in the two groups received in hospital.

Children who showed relatively high levels of self-rated depressive symptomatology on admission to hospital tended to receive fewer 
visits than children who did not rate themselves as highly. For example, nearly $80 \%$ of the children with the highest self-rated depression scores received either no or only one visit during the two weeks, whereas $83 \%$ of the children who rated themselves as being relatively free of depressive symptoms on admission, received two or more visits.

The number of visits by parents, relatives and friends to the child in hospital did not influence the fears and anxieties reported by children as assessed on the Hospital Fears Rating Scale.

\section{Age,sex and reasons for hospitalisation}

While the age range, between 6 and 12 years, seems broad for this kind of study, no statistically significant relationships, or patterns of association were found between age and any of the other variables assessed in the study. This was the case, rather surprisingly, even with the children's responses to the Hospital Fears Rating Scale. There was no indication, for example, that younger children were more fearful about the setting and routines of an hospital environment, than were older children.

With regard to sex, boys tended to show higher levels of depressive symptomatology on all the rating scales (including the adult rating) as compared to girls, even though the differences were not statistically significant.

As might be expected, children admitted with fractures tended to rate themselves as more depressed on admission than children admitted for any other reason, although there were no differences in adult ratings of the two groups. On the second rating, children admitted for reconstruction and repair rated themselves lower on depressive symptomatology, even though their baseline levels were quite low to begin with.

\section{DISCUSSION}

A very large proportion of the 30 children assessed in this study, two weeks after admission to an orthopaedic ward, were rated by ward sisters as showing high levels of depressive symptomatology, according to the DSM-III(R) criteria. Objectively, the children were described as showing a depressed mood, commonly together with symptoms like weight loss, loss of energy, insomnia and retarded motor activity.

The most frequent depressive experience reported by the children themselves was the feeling of loneliness. This confirms the assertion that a child's separation from customary social relationships and the psychological support provided by them, is the main determinant of depressive feelings during hospitalisation. This conclusion was supported, also, by the responses children gave to items tapping these feelings on the Hospital Fears Rating Scale. These responses indicated that the separation of the child from the home was designated by more of the children, to be disturbing than were responses to the hospital environment.

The discrepancy between child and adult ratings of depressive symptoms is in accord with reports from other studies. Children tend to report fewer symptoms than parents or clinicians, a finding which has been attributed to the idea that children are less likely to view many of their behaviours as problems, particularly those which concern eating, sleeping and weight loss (Kazdin, Colbus \& Rodgers, 1986).

Nearly a third of the children rated themselves as feeling depressed, on admission, and their feelings remained unabated during the two week period of hospitalisation under study. Associated with these feelings were, in various combinations, low visiting rates by family and friends, hospitalisation fro fractures, and a home situation in which the mother was not the child's primary care-giver. These conditions may place stressors on children which act in concert with hospitalisation, to place a child at risk for persistent depressive feelings. One child reported suicidal thoughts which persisted from assessment on admission, until discharge two weeks later. From this study, it would appear that hospitalisation is a further stress in the lives of some children who are, prior to hospitalisation, generally unhappy or depressed.

A few children showed a reduction in depressive feelings over the period spent in hospital. There have been reports from other studies of children showing reductions in behaviour problems following hospitalisation (Siegel, 1988). Virtually no attention has been given to the potentially positive effects of hospitalisation for children, particularly for children from multi-problem, low-income families. There have been suggestions that for such children, the hospital could serve as a temporary respite from a chaotic home situation, by providing a structured environment in an atmosphere of support and caring, created by adults who are concerned with the child's physical and emotional well-being (Siegel, 1988).

It is clearly important that all opportunities should be used to provide children from low-income families with experiences that may enhance or maintain their ability to cope with stressful life circumstances. For hospitals to take the opportunity provided by a child's admission, attention will have to be given to devising appropriate information-giving and support programmes, and to promoting visiting programmes to help children who may be relatively isolated from friends and family for extended periods of time.

The sample studied here was small and, unfortunately, relatively heterogenous with regard to the reasons for hospitalisation. For example, it might be anticipated that children admitted to hospital for reasons of repair of orthopaedic abnormalities, would experience positive feelings that may compensate for the separation from family and discomfort normally entailed by surgery. They would also likely have had a fairly extended period of notice of their impending hospitalisation, which would have facilitated social and psychological preparation for the experience. In contrast, children admitted with trauma may have had to deal with a negative experience, associated with their fractures, as well as with a sudden separation from their families and disruption of their day-to-day lives.

Despite the above shortcomings, this study has indicated that hospitalisation, for orthopaedic child patients at least, is an experience which is associated with the development of depressive symptomatology. In addition, it is also associated with the maintenance of feelings of sadness and loneliness in children who arrive at hospital already feeling low about themselves and their circumstances. For a few children, hospitalisation appears to provide opportunities for positive experiences. It is clear that children's feelings and experiences in hospital are complicated, linked also to the child's medical condition and past and current social circumstances. Nonetheless, the findings attest to the importance of developing positive and purposeful procedures to improve children's mental state when they have to be hospitalised. This is particularly important in South Africa, where children are admitted to hospitals long distances from their homes and communities, and are placed in situations which demand of them that they draw on their own resources to adapt to strange circumstances. procedures and people.

\section{REFERENCES}

American Psychiatric Association (1987). Diagnostic and Statistical Manual of Mental Disorders (3rd Edition). Washington: American Psychiatric Association.

Asarnow, J.R. \& Carlson, G. (1985). Depression Self-Rating Scale: utility with child psychiatric inpatients. Journal of Consulting and Clinical Psychology, 53, 491-499.

Birleson, P. (1981). The validity of depressive disorders and the development of a self-rating scale: a research report. Journal of Child Psychology and Psychiatry, 22, 73-88.

Blumberg, M.L. (1977). Depression in children in a general psychiatric ward. American Journal of Psychotherapy, 32, 20-32.

Bowlby, J. (1960). Grief and mouming in infancy and early childhood. Psychoanalytic Study of the Child, 15, 9-52. 
Bowlby, J. (1980). Attachment and Loss, (Vol.3). New York: Basic Books.

Freud, A. (1952). The role of bodily illness in the mental life of children. Psychoanalytic Study of the Child, Z 69-81.

Kazdin, A. (1990). Childhood Depression. Journal of Psychology and Psychiatry, 31, 121-160.

Kazdin, A., Colbus, D. \& Rodgers, A. (1986). Assessment of depression and diagnosis of depressive disorder among psychiatrically disturbed children. Journal of Abnormal and Child Psychology, 14, 499-515.

Lambert, S.A. (1984). Variables that affect the school-age child's reaction to hospitalisation and surgery: A review of the literature. Maternal Child Nursing Journal, 13, 1-18.

Langford, W.S. (1961). The child in the paediatric hospital: adaptation to illness and hospitalization. American Journal of Orthopsychiatry 31, 667-684.

Melamed, B. \& Siegel, L. (1975). Reduction in anxiety in children facing hospitalisation and surgery by use of filmed modelling. Journal of Consulting and Clinical Psychology, 43, 511-521.
Reite, M., Short, R., Seiler, C. \& Pauley, M. (1981). Attachment, loss and depression. Journal of Child Psychiatry, 22, 141-169.

Robins, P.M. (1987). Coping responses and adaptational outcomes of children undergoing orthopaedic surgery. Journal of Clinical Child Psychology, 6, 251-259.

Rutter, M. (1981). Maternal Deprivation Reassessed. New: Penguin.

Siegel, L. (1988). Measuring children's adjustment to hospitalisation and to medical procedures. In P. Karoly (Ed.), Handbook of Child Health Assessment: Bio-psychosocial Perspectives (pp. 265-303). New York: John Wiley \& Sons.

Spitz, R.A. (1945). Hospitalise: an inquiry into the genesis of psychiatric conditions in early childhood. This Annual, 1.

Trad, P.V. (1987). Infant and Childhood Depression: Developmental Factors. New York: John Wiley \& Sons.

Vernon, D., Foley, J \& Schulman, J. (1967). Effects of mother-child separation and birth order on young children's responses to potentially stressful experiences. Journal of Personality and Social Psychology, 5, 162-174.
Yap, J.N. (1988). The effects of hospitalisation and surgery on children: a critical review. Journal of Applied Developmental Psychology, 2, 349-358.

Yarrow, L.J. (1964). Separation from parents during early childhood. Review of Child Development Research, (Vol.1). National Institute of Mental Health.

Ms Malmsey Rangaka M.Soc.Sc. Counsellor.

University of Bophutatswana

Ms. Cynthia Rose M.A. (Soc.Sc.) Research Assistant, Institute for Behavioural Sciences, University of South Africa

Professor Linda Richter PhD Visiting Professor, Department of Paediatrics and Child Health.

University of the Witwatersrand. 